\title{
Presence of b- and c-Type Cytochromes in the Membrane of Escherichia coli Induced by Trimethylamine $N$-oxide
}

\author{
Morihiko SaKaguCHI* and Akira KaWAI* \\ (Received March 20, 1978)
}

\begin{abstract}
The presence of b- and c-type cytochromes has been examined in membrane fragments from Escherichia coli grown anaerobically in the presence of trimethylamine $N$-oxide (TMO) (TMOinduced cells). The amounts of both the cytochromes in the membrane were compared with those of cells grown in the presence of nitrate (nitrate-induced cells). After the membrane fragments were treated with acid-acetone, pyridine hemochrome spectra were taken of the fractions soluble and insoluble in acid-acetone. The spectra of the soluble fractions from both TMO- and nitrateinduced cells had typical protoheme peaks with the maxima at $556 \mathrm{~nm}, 525 \mathrm{~nm}$, and $420 \mathrm{~nm}$, suggesting the presence of b-type cytochromes. The amount of protoheme in TMO-induced cells was much smaller than that in nitrate-induced cells. The spectra of the insoluble fraction from TMOinduced cells only, contained the peaks of heme $c$ with the maxima at $550.5 \mathrm{~nm}, 521 \mathrm{~nm}$, and $415 \mathrm{~nm}$, indicating the presence of c-type cytochromes in the membrane. The estimated heme concentration was about $0.4 \mathrm{nmol} / \mathrm{mg}$ protein.

The roles of the b- and c-type cytochromes are discussed in relation to the electron transport system of TMO reduction in E. coli.
\end{abstract}

It is well known that trimethylamine (TMA) is one of the major components of the smell of spoiled marine fish and shell fish and that TMA formation results from the reduction of trimethylamine $\mathrm{N}$-oxide (TMO) by putrefactive bacteria. However, little information is available on a precise mechanism of the reduction in bacterial cells.

In Escherichia coli we have reported that formate and NADH effectively reduce ${ }^{14} \mathrm{C}$-TMO in the presence of membrane fragments from cells induced by $\mathrm{TMO}^{11}$. These physiological reductants can also reduce cytochromes in the membrane fragments $^{21}$. Furthermore, the reoxidation by TMO of the reduced cytochromes has been observed, indicating the participation of this pigment in TMO reduction as one of electron carriers between the reductants and the oxide. Based on the fact that 2-heptyl-4-hydroxyquinoline $\mathrm{N}$-oxide (HOQNO) inhibited the reduction of ${ }^{14} \mathrm{C}-\mathrm{TMO}$, b-type cytochromes were suggested as a probable candidate for the carriers ${ }^{11}$. In overall electron flow from formate or NADH to TMO, it was predicted that TMO reductase linked to reduced methylviologen can also be an electron carrier. The following scheme was thus proposed as a possible mechanism for the reduction of TMO occurring in the membrane of $E$. coli:

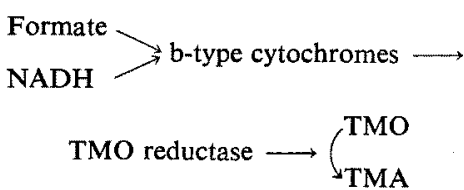

As reported in the preceding paper ${ }^{2}$, the spectra recorded at low temperature $(77 \mathrm{~K})$ revealed the existence of multiple components of the cytochromes in the membrane. After the reoxidation by TMO, some components remained in a reduced form in the presence of HOQNO but another component was rapidly oxidized beyond the inhibition by HOQNO, suggesting the involvement of c- as well as b-type cytochromes in the process of TMO reduction.

In the present investigation, therefore, we confirm the presence of b- and c-type cytochromes as well in the membrane fragments by taking spectra of pyridine hemochromes after treatment of the fragments with acid-acetone. For comparison of the results, both the different types of the pigments are determined with cells induced by nitrate. This nitrate-induced cells are known to possess cytochrome $b_{1}$ in their membranes. ${ }^{31}$

* The Research Institute for Food Science, Kyoto University, Uji, Kyoto, 611, Japan（坂口守彦. 河合音 京都大学食䊣科学研究所). 


\section{Materials and Methods}

Growth of Organisms and Preparation of Membrane Fragments

Escherichia coli (IFO 3301) was grown under the same condition as described previously (TMOinduced cells) ${ }^{\prime \prime}$. Nitrate-induced cells were obtained on the culture medium supplemented with sodium nitrate at a concentration of $2.1 \mathrm{~g} / \mathrm{l}$ instead of TMO. After harvested in the later log phase of growth, cells were washed once with $0.05 \mathrm{M}$ potassium phosphate buffer $(\mathrm{pH}$ 7.2) and changed to spheroplasts by the method of Miura and Mizushima". Spheroplasts were disrupted osmotically in $0.1 \mathrm{M}$ Tris- $\mathrm{HCl}$ containing $5 \mathrm{~mm}$ $\mathrm{MgCl}_{2}$ and $0.05 \mathrm{M}$ sodium phosphate ( $\mathrm{pH}$ 7.2), then centrifuged at $6,000 \times \mathrm{g}$ for $10 \mathrm{~min}$ to remove unbroken cells. The supernatant was centrifuged at $48,000 \times \mathrm{g}$ for $30 \mathrm{~min}$ to collect membrane fragments. The membrane fragments of the resulting pellet were directly submitted to fractionation of hemes.

Fractionation of Hemes and Recording of Pyridine Hemochrome Spectra

The membrane fragments were extracted with 20 volumes of $4 \% \mathrm{HCl}$-acetone ( $\mathrm{vol} / \mathrm{vol}$ ) at $0^{\circ} \mathrm{C}$, followed by centrifugation at $2,000 \times \mathrm{g}$ for $10 \mathrm{~min}$. The supernatant fluid (acid-acetone-soluble fraction) was evaporated to near dryness in vacuo. The residue was dissolved in $50 \%$ aqueous pyridine ( $\mathrm{vol} / \mathrm{vol}$ ), then added an equal volume of $0.2 \mathrm{~N}$ $\mathrm{NaOH}$ to form pyridine hemochromes. The precipitate (acid-acetone-insoluble fraction) was suspended in $10 \mathrm{ml}$ of $50 \%$ aqueous pyridine ( $\mathrm{vol} /$ vol), and added an equal volume of $0.2 \mathrm{~N} \mathrm{NaOH}$. $\mathrm{Na}_{2} \mathrm{~S}_{2} \mathrm{O}_{4}$-reduced minus air-oxidized difference spectra of these pyridine hemochromes for the acid-acetone-soluble and -insoluble fractions were calculated from $\triangle A_{556-540}$ for protoheme and $\Delta A_{551-536}$ for heme c, respectively, using mM $\varepsilon=20$ for both the hemes ${ }^{5}$.

\section{Determination of Protein}

Contents of protein in the membrane fragments were estimated by the method of LowRY et al. ${ }^{61}$ with bovine serum albumin as a standard.

\section{Results}

Both the membrane fragments from TMOand nitrate-induced were reddish brown in color. The cytochrome spectra of the fragments, however, were different each other, as reported previously ${ }^{2}$. The fragments from TMO-induced cells demonst- rated the spectrum having 3 peaks with the maxima at $555 \mathrm{~nm}, 526 \mathrm{~nm}$, and $427 \mathrm{~nm}$ in the region of $400 \mathrm{~nm}$ to $650 \mathrm{~nm}$. The fragments from nitrateinduced cells, which are generally recognized to contain cytochrome $b_{1}{ }^{3,71}$, exhibited the spectrum with the maxima at $560 \mathrm{~nm}, 530 \mathrm{~nm}$, and $430 \mathrm{~nm}$. In order to examine the types of cytochromes, we recorded pyridine hemochrome spectra for the fractions soluble and insoluble in acid-acetone.

Fig. 1 illustrates the spectra for the acid-acetonesoluble fraction of TMO- and nitrate-induced cells. Three pronounced peaks with the maxima at $556 \mathrm{~nm}, 525 \mathrm{~nm}$, and $420 \mathrm{~nm}$ were detected in TMO-induced cells and at the same positions the maxima could also be found in nitrate-induced cells. They are exactly identical with the absorption maxima of $\alpha, \beta$, and $\gamma$ peaks of protoheme ${ }^{5}$, respetctively, indicating the presence of this compound in both the membranes of TMO- and nitrate-induced cells.

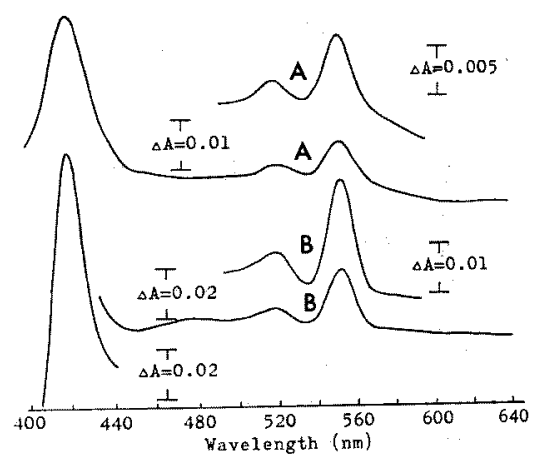

Fig. 1. Pyridine hemochrome difference spectra of the acid-acetone-soluble fraction of the membrane. fragments from TMO- and nitrate-induced cells.

The membrane fragments from TMO- and nitrate-induced cells containing $60 \mathrm{mg}$ and $33 \mathrm{mg}$ protein, respectively, were extracted with acidacetone. The soluble fraction from respective induced cells was evaporated and suspended in $20 \mathrm{~m} l$ and $25 \mathrm{~m} l$ of alkaline pyridine. Upper traces indicate the expansion of lower traces of $500 \mathrm{~nm}$ to $600 \mathrm{~nm}$ for each specimen. A, TMO-induced cells; B, nitrate-induced cells.

Fig. 2 shows the spectra for the acid-acetoneinsoluble fraction of TMO- and nitrate-induced cells. In TMO-induced cells, there were 3 distinct peaks with the maxima at $550.5 \mathrm{~nm}, 521 \mathrm{~nm}$, and $415 \mathrm{~nm}$, whereas in nitrate-induced cells no peak could be detected. The maxima seen in the spectrum of TMO-induced cells are the same as those of $\alpha, \beta$, and $\gamma$ peaks of heme $c^{5}$, respectively 


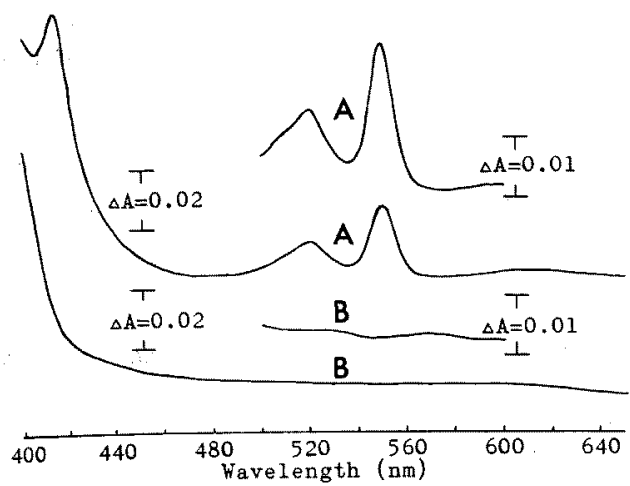

Fig. 2. Pyridine hemochrome difference spectra of the acid-acetone-insoluble fraction of the membrane fragments from TMO- and nitrateinduced cells.

The membrane fragments from TMO- and nitrate-induced cells containing $93 \mathrm{mg}$ and $90 \mathrm{mg}$ protein, respectively, were extracted with acidacetone. The insoluble fraction from both the induced cells was suspended in $30 \mathrm{ml}$ of alkaline pyridine. A, TMO-induced cells; B, nitrateinduced cells

suggesting the presence of c-type cytochromes in this cells.

Table 1 shows protoheme and heme c concentrations which were calculated from the respective $a$ peak heights of Fig. 1 and Fig. 2. TMO-induced cells possessed heme $\mathrm{c}$ about 3 times as high as that of protoheme in the membrane. On the other hand, nitrate-induced cells were rich in protoheme but heme c was absent. Generally, E. coli has soluble cytochrome $c$ as a cell constituent $t^{8,9)}$.

Table 1. Heme concentration in the membrane fragments from TMO- and nitrate-induced cells

\begin{tabular}{ccc}
\hline \multicolumn{1}{c}{ Cells } & Protoheme* & Heme $\mathrm{c}^{*}$ \\
\hline TMO-induced & 0.12 & 0.38 \\
Nitrate-induced & 0.91 & 0 \\
\hline$*$ nmol/mg protein & &
\end{tabular}

There might still be the possibility that the soluble pigment contaminates the membrane fragments from TMO-induced cells. This possibility, however, was excluded by the finding that the heme $c$ concentration showed no change before and after washing of the fragments with $0.3 \mathrm{M} \mathrm{NaCl}$. Another experiment with the fragments which were prepared from spheroplasts once washed with $0.75 \mathrm{M}$ sucrose plus $0.3 \mathrm{M} \mathrm{NaCl}$ also showed no effect of this washing on the heme concentration.

\section{Discussion}

As reported previously ${ }^{11}$, the participation of the b-type cytochromes in TMO reduction was suggested by the finding that HOQNO inhibited the electron transport from formate and NADH to TMO. The pyridine hemochrome spectrum of the acid-acetone-soluble fraction (Fig. 2A) indicates the presence of protoheme in the membrane fragments from TMO-induced cells. Protoheme includes the prosthetic group of b-and o-type cytochromes both of which have been found in $E$. coli $^{10-121}$. The relative concentration of the o-type pigment is reportedly less than half that of the b-type pigments even in aerobically grown cells ${ }^{11,121}$ where the o-type functions as a terminal carrier of electron to molecular oxygen ${ }^{101}$. Although not determined with TMO-induced cells, the o-type, if exists in the membrane fragments, would have little functional activity in such an anaerobic system as the reduction of TMO. The protoheme in this case, therefore, must chiefly be included in the b-type.

The membrane fragments of TMO-induced cells had much the lower concentration of protoheme than those of nitrate-induced cells possessing cytochrome $b_{1}$ (Table 1). It would, however, be noted that TMO-induced cells have b-type cytochromes distinguishable from $b_{1}$ in the lowtemperature spectra ${ }^{21}$; the latter showed only one maxima of the $\alpha$ peak at $556 \mathrm{~nm}$ while the former exhibited neither maximum nor distinct shoulder at this wavelength. The spectrum of the membrane fragments from TMO-induced cells had the maxima and shoulders at $549.5 \mathrm{~nm}, 551 \mathrm{~nm}$, $552.5 \mathrm{~nm}$, and $558 \mathrm{~nm}$ in the $\alpha$ peak region, indicating the presence of multiple cytochrome components. Both the $552.5 \mathrm{~nm}-$ and $558 \mathrm{~nm}$ components were considered to be the b-type since they were without the reoxidation by TMO in the presence of $\mathrm{HOQNO}{ }^{21}$.

The finding of heme $c$ in the acid-acetoneinsoluble fraction strongly support the idea that ctype cytochromes exist in the membrane. This cytochromes are the only pigment for which the heme portion is unextractable with acid-acetone. As suggested in the previous paper ${ }^{2}$, this pigment probably corresponds to the components reoxidized by TMO beyond the HOQNO-inhibition and hence would have the maxima at $549.5 \mathrm{~nm}$ and/or $551 \mathrm{~nm}$ in the spectrum.

Since c-type cytochromes generally give higher standard redox potentials than b-type pigments, 
the c-type pigments can properly be placed at the position just after the b-type in the electron transport system. The overall sequence of TMO reduction can be summarized as follows:

$$
\begin{aligned}
& \begin{array}{l}
\text { Formate } \longrightarrow \text { b-Type } \\
\text { cytochromes }
\end{array} \longrightarrow \begin{array}{l}
\text { c-Type } \\
\text { cytochromes }
\end{array} \longrightarrow \\
& \begin{array}{l}
\text { TMO } \\
\text { reductase }
\end{array} \underbrace{\text { TMO }}_{\text {TMA }}
\end{aligned}
$$

The reduced form of the c-type pigment is produced by that of the b-type which accepts electron from formate and NADH assumingly in an indirect way through formate dehydrogenase and flavoprotein, respectively. The reduced c-type cytochromes in turn reduce TMO reductase and finally the enzyme catalyzes the reduction of TMO to TMA.

The role of cytochrome $b_{1}$ in nitrate reduction was well investigated ${ }^{3}$, whereas the data indicating the involvement of c-type cytochromes are rather scanty in aerobic and anaerobic electron transport in $E$. coli. The participation of cytochrome $c_{552}$ in nitrite reduction was reported by FuJITA and SATO $^{81}$ but this protein is soluble, not tightly bound to the membrane. In TMO reduction the c-type cytochromes together with the b-type are actually functioning in the membrane of cells, as evidenced by the fact that the reduced form of these cytochromes was completely changed to the oxidized form by $\mathrm{TMO}^{2 !}$.

With regard to the c-type cytochromes our preliminary observation could provide evidence on the induced synthesis: with the increase of TMO concentrations in the medium the cytochromes concomitantly increased in the membrane. The induced synthesis of TMO reductase depending on the inducer concentration was reported previously ${ }^{13}$, suggesting close association of the pigment with the enzyme, which is also membranebound in cells ${ }^{14}$.

As observed in the aerobic electron transport in $E$. coli, the site for HOQNO-inhibition has been placed at ubiquinone levels situated before and after cytochrome $b_{1}{ }^{15)}$. If ubiquinone (or menaquinone ${ }^{16}$ ) plays a role of the electron carrier in TMO reduction as well, it can act at least between the b- and c-type cytochromes. Details on this aspect are to be given in a future report.

\section{References}

1) M. Sakaguchi and A. Kawai: Bull. Japan. Soc. Sci. Fish., 43, 437-442 (1977).

2) M. SAKAGUChI and A. KaWAI: Bull. Japan. Soc. Sci. Fish., 44, 511-516 (1978).

3) A. H. Stouthamer: Adv. Microbial Physiol., 14, 315-375 (1977).

4) T. MruRA and S. Mizushima: Biochim. Biophys. Acta, 193, 268-276 (1969).

5) J. F. SPERRY and T. D. Wilkins: J. Bacteriol,, 125, 905-909 (1976).

6) O. H. Lowry, N. J. Rosebrough, A. L. Fall, and R. J. RANDALL: J. Biol. Chem., 193, 265-275 (1951).

7) S. Taniguchi and E. ItagaKI: Biochim. Biophys. Acta, 44, 263-279 (1960).

8) T. FujrtA and R. SATo: J. Biochem., 60, 691-700 (1966).

9) C. T. Gray, J. W. T. Wimpenny, D. E. Hughes, and M. RANLETT: Biochim. Biophys. Acta, 67, 157-160 (1963).

10) L. N. Castor and B. Chance: J. Biol. Chem., 234, 1587-1592 (1959).

11) J. A. AsCroft and B. A. HADDock: Biochem. $J ., 148,349-352$ (1975).

12) P. K. Poole and B. A. HADDock: Biochem. J., 152, 537-546 (1975).

13) M. SaKaguchi and A. KaWaI: Bull. Japan. Soc. Sci. Fish., 41, 661-665 (1975).

14) M. SaKaguchi and A. KaWAi: Bull. Japan. Soc. Sci. Fish., 41, 707 (1975).

15) G. B. Cox, N. A. Newton, F. Gibson, A. M. SNoswell, and J. A. HAmilton: Biochem. J., 117, 551-562 (1970).

16) B. A. HADDOCK and C. W. Jones: Bacteriol. Rev., 41, 47-99 (1977). 